\title{
Economics
}

2020; 9(1): 17-20

$\mathrm{http}: / /$ www.sciencepublishinggroup.com/j/eco

doi: 10.11648/j.eco.20200901.13

ISSN: 2376-659X (Print); ISSN: 2376-6603 (Online)

\section{The Economic Cost of Gender Inequality: The Global Progress and Creating Change}

\author{
June Choon Wai Yee*, Kenneth Lee Kwing-Chin \\ School of Pharmacy, Monash University Malaysia, Selangor, Malaysia \\ Email address: \\ choon.wai.yee@monash.edu (J. C. W. Yee), choonwaiyee@gmail.com (J. C. W. Yee), kenneth.lee@amonash.edu (K. L. Kwing-Chin) \\ ${ }^{*}$ Corresponding author
}

\section{To cite this article:}

June Choon Wai Yee, Kenneth Lee Kwing-Chin. The Economic Cost of Gender Inequality: The Global Progress and Creating Change. Economics. Vol. 9, No. 1, 2020, pp. 17-20. doi: 10.11648/j.eco.20200901.13

Received: January 29, 2020; Accepted: February 28, 2020; Published: March 6, 2020

\begin{abstract}
Background: Gender inequality is a contentious matter that cuts across economic and social aspects that are still prevalent globally. It is often framed as a problem of women, but in reality, it is more than that. Gender gaps that include lack of under-representation of women in the workforce and especially in senior positions are significant issues that pose substantial economic costs to countries. Gender inequality often manifested as discrimination in their advancement in careers, and higher time spent on household and care duties compared to men. Methods: The economic loss that results from gender gaps were reviewed. Against the same backdrop, countries with progressive and more inclusive policies were analysed in order to draw lessons that could be potentially useful for countries that are heading the direction of narrowing if not close the gender gaps. Results: Despite there are more initiatives to address this alarming issue over the years, progress towards gender equality is still far from satisfactory and gaps remain even in the dawn of 2020. Much remains to be done. To that end, some potential solutions and policies that have proven to be cost- and time effective in pursuit of gender equality are discussed in this paper. Conclusion: We conclude that there is no blanket solution for addressing gender inequality. Achieving gender equality will most likely to remain an uphill battle, but not one that is impossible to be overcome.
\end{abstract}

Keywords: Gender, Inequality, Economic, Costs

\section{Introduction}

In many countries, the average educational attainment by girls remains lesser than boys and literacy level is higher for men than women. Apart from these gender gaps in educational attainment, gender discrimination and social standards continue to shape the terms of female labour force participation. Women are less likely than men to join the workforce and to work for pay. Even when they do, they are more likely to work on a part-time basis, a more informal sector, or positions with lower pay. These drawbacks are converted into significant gender gaps in earnings, which in sequence, reduce women's bargaining power and voice.

On the whole, gender inequality affects women and girls in ways that deny them their fundamental human rights. This lack of equal opportunities for girls and women causes substantial economic costs not just for them, but also for their families and countries. Achieving, or at least, narrowing the gender equality gaps would create a more inclusive, sustainable and thriving ecosystems.

Much work has been done within this space over the years. The Global Gender Gap Report has monitored progress in closing gender gaps since 2006 [1]. A recent 2019 report published by the International Labour Office concluded that there is a long way to go in this regard and the journey to equality is far from over [2]. In the European Union (U.N.), progress in gender equality is encouraging, although this progress can be accelerated. The 2019 Report on equality between women and men in the EU also mentioned that the recent \#MeToo movement helped in bringing women's rights back in the public attention. The on-going evaluation of the principle of equal pay in the EU will provide the foundation to reinforce this principle and close the gender inequality gap down.

Although still lacking behind, developed and developing countries have made progress. Our main objectives are to have a better understanding of why the progress is still slow and what are the initiatives that could be taken to accelerate it. 
This article presents a clear and detailed case of economic costs of gender inequality. There is a need to review various progressive initiatives and successful policy implementation in countries that are advancing to narrow and eventually close the gaps in gender inequality.

\section{Methodology}

A review of literature to look into successful interventions and how these can be implemented in several areas to improve employment opportunities and earnings for women was performed. Scandinavian countries such as Finland, Norway, and Sweden have been known to lead the way in narrowing gender gaps compared to other countries. To this end, we reviewed the initiatives and successful policy implementations in these countries to compare the approaches, success rates and discuss the best way forward in addressing this pressing concern.

\section{Results}

After its global report in 2015, "The power of parity: How advancing women's equality can add $\$ 12$ trillion to global growth" McKinsey explored the challenge of gender inequality in the Asia Pacific (APAC), one of the most economically dynamic regions in the world [3]. "The Power of Parity: Advancing Women's Equality in Asia Pacific" published in 2018, reported that gender inequality is high overall in APAC, with significant variations among countries [3]. It was projected that APAC countries could add $\$ 4.5$ trillion to their collective annual GDP by 2025 , a 12 per cent increase over the business-as-usual trajectory if women's equality is advanced. "Global Gender Gap Report 2020" by the World Economic Forum compared gender gaps across four dimensions:

economic participation and opportunity, educational attainment, health, and political empowerment [4]. Under the Economic Participation and Opportunity sub-index, only 58 per cent of the gap had been closed thus far and the presence of women in the labour market was persistently less than men. In emerging market like Malaysia, woman labour force participation stands at only 55.2 per cent, a figure far from the male rate of 80.4 per cent [5]. Also, gender gaps tend to widen in parallel with seniority level. Globally, only 36 per cent of senior private sector's managers and the public sector's officials are women [3]. The presence of women on corporate boards or as top business leaders is even more limited: a woman leads only 18.2 per cent of firms globally. On average, 22.3 per cent of board members in OECD countries are women, with an even lesser representation in emerging economies [3].

In another report by the WorldBank Group published in 2018 , women account for a mere 38 per cent of human capital wealth compared to 62 per cent for men globally [6]. Especially glaring in low- and lower-middle-income countries, women account for a third or less of human capital wealth. The report also revealed that on a per capita basis, gender inequality in earnings could lead to losses in a wealth of $\$ 23,620$ per person globally. Losses vary between regions and countries due to levels of human capital wealth, and thus losses in wealth due to gender inequality, tend to rise in absolute values with economic development. Against the same backdrop, the most significant losses occur in OECD countries. One hundred forty-one countries included in the analysis, the loss in human capital wealth due to gender inequality is estimated at $\$ 160.2$ trillion with the assumption that women are earning as much as men. This amount comes up to about twice the value of GDP globally. In other word, human capital wealth could increase by 21.7 per cent globally, and total wealth by 14.0 per cent with gender equality in earnings. The report identified two critical drivers for women to have fewer earnings and thereby lower human capital wealth than men were found to be lower labour force participation rates and fewer hours worked in the labour market, substantiated with lower pay. These factors denied the productivity of many women due to the social norms and how they were relegated to unpaid care and work.

Women's under-representation in business-leadership positions is a global issue that needs to be addressed. Several factors contributed to this. One of the critical factors is the unequal burden of household and care responsibilities that women continue to shoulder. Globally, women still spend multiple-folds as much time as men on these responsibilities. Even in countries like the United States, women spend almost twice as much time as men on unpaid domestic work [7]. The responsibilities shouldered by women is not only due to overall standards of living, as they still spend more than four times that of men even in advanced economies such as Japan [8]. A negative gender gap relationships between women's relative amount of time spent on unpaid domestic work, economic participation and opportunity are consistent across developed and developing countries. Reducing the gender gap in labour force participation by 25 per cent by 2025 could (through increases in the size of their labour forces) add 1 percentage point to projected baseline gross domestic product growth across the Organisation for Economic Co-operation and Development (OECD) over the period 2013-25, and almost 2.5 percentage points if gender participation gaps were halved by 2025 [9]. Inaction is costly, and the economic case for gender equality is clear.

\section{Discussions}

Despite women's dramatic gains in education, their representation in leadership roles remains low [10]. Women's underrepresentation in leadership restricts the presence of female voices in making decisions and denies girls and young women of positive role models. Many OECD countries have introduced policies that encourage gender balance on boards and in senior management. Affirmative action measures to move more women into leadership have been implemented. Battling stereotypes requires a broad, societal acceptance that women are indeed capable of achieving as much as men.

Today, motherhood is still made to look as though it is 
somewhat a disadvantage. Mothers are often overlooked in promotions. For some, child care is unavailable, unaffordable, or inappropriate. Many families with young children are forced to choose between spending a substantial portion of their pay on child care or finding a cheaper, but potentially lower-quality care option, or giving up the workforce altogether to become a full-time caregiver. Whether due to high cost, limited availability, or inconvenient program hours, child care challenges are driving parents out of the workforce at a worrying rate. In 2016 alone, an estimated 2 million parents made career sacrifices due to problems with child care [11].

Child care has become a barrier to work, often for mothers, who disproportionately shoulder more unpaid caregiving responsibilities when child care is not available or affordable [12]. 3 In another 2018 survey conducted by the Center for American Progress, mothers were 40 per cent more likely than fathers to report that they had personally felt the negative impact of child care issues on their careers [13]. Besides, it is the mother who often compelled to make job decisions based on child care considerations regardless of the interest of their financial situation or career aspirations. Working hours can be long and unpredictable, in addition to having to pay their shares for rising health care and living costs. Women's earning capacity stalled after having children and mothers spend considerably more time taking care of children than fathers do [14]. This opportunity cost translates into women's inability to fully participate in the labour force, resulting in financial stability and livelihoods suffer. Very few parents have sufficient financial resources to choose between work and family.

In the U.S., businesses suffer a loss of an estimated \$12.7 billion annually because of their employees' child care challenges. Nationally, the cost of lost earnings, productivity, and revenue due to the child care crisis totals an estimated \$57 billion each year $[15,16]$. This reiterates the fact that the issue of gender inequality has spiral effects. When policymakers talk about choices that parents can make, they only target mothers. A man hardly gets asked how he divides his time between work and family. Women's choices have long been restricted before the term 'choice' became increasingly politicised in shaping policy debates. In 1981, Nobel-winning economist Gary Becker in his landmark work, "A Treatise on the Family", argued that home behaves like a free-market where each family functions as a small factory, with each member making rational choices to maximize value [17]. Becker explored the economic implications of the most personal decisions, such as choosing a spouse, and allocation of time to child care as well as to careers. On decision making, many women still feel guilty and even shamed by others, for choosing work and leaving their child in inadequate care. They deliberately choose to work in scaled-back jobs, giving up on the prospects of advancing their career or in other decisions that they would not have made under different circumstances. The shift in societal attitudes toward women's role is a powerful force that can enable-or hold back - progress of gender inequality. It is time to stop framing the term 'choice' as a woman's decision and ability to choose between work and family when, in reality, it often feels like there is no choice at all. Cultural and social transformations will not happen overnight. More policies with cost- or time-effective solutions to care needs, such as child care within a workplace and flexible working options are much needed. Realignment of attitudes and burden of household and care duties such as longer paid maternity and paternity leave have long been debated. Paternal leave with stronger financial incentives is essential for gender equality in paid and unpaid work, as it encourages parents to share caregiving more equally and allows mothers' labour market participation.

Most gender-equal countries are all dominated by Nordic countries [3]. To date is Iceland remains the most gender-equal. It has closed over 85 per cent of its overall gender gap. Norway follows Iceland (83.5 per cent, Sweden and Finland 82.2 per cent). In February 2020, Finland's new government announced one of the most equitable parental leaves policies in Europe [18]. All Finnish parents are now entitled to the same parental leave, nearly seven months' paid leave, half of which will be non-transferrable, while all references to maternity and paternity leave are being scrapped. Paid allowance will increase to a combined 14 months, which works out as 164 days per parent. It is estimated that the changes will cost an extra $€ 100 \mathrm{~m}$ (£84m; \$110m). The government's message is loud and clear: all parents, regardless of their background and circumstances, are equal in this endeavour. Within the same context, another study of four countries; namely the U.S., Australia, the UK and Denmark found that fathers who had paternity leave were more likely to share care duties like feeding, dressing, bathing and spending quality with their child at the end of the leave. Hence, this led to another rather intriguing school of thinking; equal parenting and shared care duties were not about the rights of the parents after all, but the rights of the child.

Its neighbour Sweden is perhaps Europe's most generous system with parental leave of 240 days each after a baby's birth. Sweden, Norway, Iceland, Estonia and Portugal were praised in a UNICEF report for offering the best family-friendly policies [19]. Nordic countries had been leading the way on giving fathers entitlement that could not be transferred to the mother. The European Union is also heading that way, with a directive giving member states three years to provide each parent with a minimum of four months' leave, including two months that are not transferrable. Lessons can be drawn from these progressive countries, that is if a country is genuinely serious about closing the gender inequality gap, the only way is to overhaul parenting policy and culture and this will have to begin to now.

The issue of affordability needs to be addressed through increases in subsidies, or the introduction or expansion of free childcare hours or more direct support from the public sector in providing new facilities for young children. Although there are more progressive organizations offering flexibility and more family-friendly policies in workplaces than ever before, the progress is still slow and uneven. There is a need for more concerted efforts to lead cultural change at both micro and 
macro level to address attitudes about women's role in society. Discrimination and biases against women need to be recognized and tackled. Gender equality and comprehensive education in the school curriculum encourages young minds to strive for more healthy and equal relationships. It is time to step up efforts through sustainable campaigns, monitoring policies directed at gender equality, more public investment, and the introduction and expansion of legal measures to ensure equal opportunities for women.

\section{Conclusion}

The practical and economic implications of gender inequality are enormous, impacting women, parents, employers, taxpayers and nations. Gender inequality is a pressing global concern that needs urgent attention. Promoting gender equality needs progressive and inclusive policies to level the playing field for women. Equality is essential in increasing the wealth of nations and enable countries to develop in a more inclusive, thriving and sustainable ways. Although there is progress in policies and affirmative action measures, gender gaps persist. Progressive policies to close the gaps of gender inequality a reality is a must-have rather than nice-to-have.

\section{References}

[1] World Economic Forum, "The Global Gender Gap Report 2018 ', 2018.

[2] International Labour Organization, “A quantum leap for gender equality - For a better future of work for all', 2019.

[3] McKinsey Global Institute, "The power of parity: How advancing women's equality can add $\$ 12$ trillion to global health," September 2015.

[4] McKinsey Global Institute, "The power of parity: Advancing women's equality in Asia Pacific," April 2018
[5] World Economic Forum, "Insight Report: Global Gender Gap Report 2020," 2019.

[6] Murad D., "Malaysia benefits by investing in women," November 2019. The Star Online.

[7] Wordon Q. and La Brierre, "The cost of gender inequality. The unrealized potential: the high cost of gender inequality in earnings," May 2018. The World Bank.

[8] Economic report of the president, "Chapter 4: The economics of family-friendly workplace policies," February 2015.

[9] Yamaguchi K., “Japan's gender gap," Finance and Development, March 2019. Vol 56, no. 1.

[10] OECD, The pursuit of gender equality: an uphill battle, OECD Publishing, Paris. 2017.

[11] The American Association of University Women, "Barriers and bias: The status of women in leadership,” 2016.

[12] Schochet L., and Malik R., "2 Million Parents Forced to Make Career Sacrifices Due to Problems with Child Care," Center for American Progress, 2017.

[13] Parker K., "Women more than men adjust their careers for family life," Pew Research Center, 2015.

[14] Halpin J., Agne K., and Omero M., "Affordable Child Care and Early Learning for All Families", Washington: Center for American Progress, 2018.

[15] Population Reference Bureau, "Progress in U.S. women's well-being stalled in recent generations," 2017.

[16] Bishop-Josef A. et al., "Want to Grow the Economy? Fix the Child Care Crisis" Washington: Council for Strong America, 2019.

[17] Becker GS., "A Treatise on the Family, "Harvard University Press, 1991.

[18] Wamsley L., "Finland's Women-Led Government Has Equalized Family Leave: 7 Months For Each Parent”, NPR, 2020.

[19] "Are the world's richest countries family friendly? Policy in the OECD and EU," UNICEF, 2019. 